\title{
RANCANGAN ULANG TATA LETAK MESIN DI PT. KOROSI SPECINDO
}

\author{
Siti Rohana Nasution dan Hari Purwanto \\ Program Studi Teknik Industri, Universitas Pancasila \\ e-mail: nasutionana@yahoo.co.id, haripurwanto1988@yahoo.com
}

\begin{abstract}
ABSTRAK
Perencanaan fasilitas merupakan salah satu upaya yang dilakukan perusahaan untuk dapat mengorganisir berbagai alat produksinya agar mampu memberikan efisiensi dari segi tata letak. PT. Korosi Specindo adalah salah satu perusahaan manufaktur yang bergerak di bidang Corrosion Monitoring System. Saat ini kondisi layout fasilitas produksi di perusahaan mengalami kendala dalam hal material handling yang kurang efisien. Hal ini dikarenakan tata letak mesin yang tidak teratur. Penelitian ini bertujuan untuk merancang tata letak mesin yang lebih baik. Berdasarkan hasil analisis menggunakan metode From To Chart, Out Flow, Tabel Skala Prioritas, dan Activity Relationship Diagram diperoleh rancangan tata letak mesin yang paling optimum. Dalam penelitian ini layout usulan dapat memperbaiki aliran material handling menjadi lebih teratur. Terjadi penurunan jarak material handling dari total jarak awal sebesar 1036,8 meter dengan layout usulan menjadi 732,3 meter. Persentase penurunan jarak material handling sebesar 29,36\%. Layout usulan juga dapat menurunkan ongkos material handling dari total ongkos awal sebesar Rp. 8666,122 menjadi Rp. 6176,184. Persentase penurunan ongkos material handling sebesar $28,73 \%$.
\end{abstract}

Kata kunci: Material Handling, Ongkos Material Handling, From To Chart, Corrosion Monitoring System

\begin{abstract}
Planning facilities is one of the company's efforts are being made to organize a variety of production tools to provide efficiency in terms of the layout. PT Korosi Specindo is one of the companies engaged in the manufacture of Corrosion Monitoring System. The current condition of the production facility in firms layout experience constraints in therm of a less efficient material handling. This is because the layout machine which is not regular. This research aim is to designing the layout of the machine the better. Based on the result of the analysis using the methode From To Chart, Out Flow, Table Priority Scale, and Activity Relationship Diagram machine layout design earned the most optimum. In this research proposal layout can improve the flow of material handling became more regular. Material handling distance decrese occured from the beginning of total distance 1036,8 meters with a layout proposal be 732,3 meters. The percentage decrease in material handling distance of 29,36\%. Layout proposal can also lower the cost of material handling from the total initial cost of Rp. 8666,122 to Rp. 6176,184. Percentage reduction in cost of material handling of $28,73 \%$.
\end{abstract}

Keywords: Material Handling, Cost of Material Handling, From To Chart, Corrosion Monitoring System

\section{PENDAHULUAN}

Rancangan fasilitas merupakan salah satu upaya yang dilakukan perusahaan untuk dapat mengorganisir berbagai alat produksinya agar mampu memberikan efisiensi dari segi tata letak. Tujuan perencanaan fasilitas yakni untuk menambah kapasitas produksi dengan cara yang paling ekonomis melalui pengaturan dan koordinasi yang efektif dari fasilitas fisik. Perancangan fasilitas-fasiltas produksi yang baik akan mampu meningkatkan efisiensi penggunaan ruang, waktu, maupun biaya pemindahan bahan. Di sisi lain, tata letak fasilitas produksi yang kurang teratur dapat menyebabkan panjangnya jarak perpindahan bahan yang dapat berakibat pada lamanya waktu proses produksi, serta meningkatkan biaya perpindahan bahan. Pada penelitian kali ini, pengamatan dilakukan di PT. Korosi Specindo.

PT. Korosi Specindo adalah salah satu perusahaan yang bergerak dalam bidang Corrosion Monitoring System. Perusahaan ini memproduksi alat untuk memonitor tingkat korosi yang terjadi di dalam pipa-pipa migas. Saat ini kondisi layout fasilitas produksi di perusahaan mengalami kendala dalam hal pemindahan bahan baku (material handling) yang kurang efisien. Hal ini dikarenakan tata letak mesin yang tidak teratur. Ketidakteraturan 
aliran proses produksi tersebut dapat membuat jarak material handling yang panjang. Oleh karena itu, dibutuhkan perancangan ulang tataletak mesin produksi untuk dapat memberikan solusi terhadap permasalahan tersebut.

PT. Korosi Specindo memiliki 2 lantai produksi. Lantai 1 memiliki luas 883,36 $\mathrm{m}^{2}$ dan lantai 2 memiliki luas $490 \mathrm{~m}^{2}$. Access Fitting Assy merupakan produk utama yang dibuat di PT. Korosi Specindo yang berfungsi untuk memonitor tingkat korosi pada pipa. Access Fitting Assy terdiri dari beberapa part/ komponen yaitu Access Fitting, Solid Plug,
Protective Cover, Coupon Holder, dan Coupon. Gambar 1 memperlihatkan ketidakteraturan aliran proses produksi saat pembuatan produk Access Fitting. Aliran proses pembuatan Access Fitting ini dapat mewakili produk yang lain, dikarenakan proses permesinan Access Fitting yang paling panjang dan mempergunakan berbagai mesin seperti mesin Cutting, Radial Drilling, Manual Lathe, CNC Lathe, CNC Milling, Manual Milling, CNC Grafir, dan Carbon Black. Walaupun untuk produk lain ada proses yang melongkapi proses pembuatan Access Fitting.

LAYOUT MESIN LANTAI 2

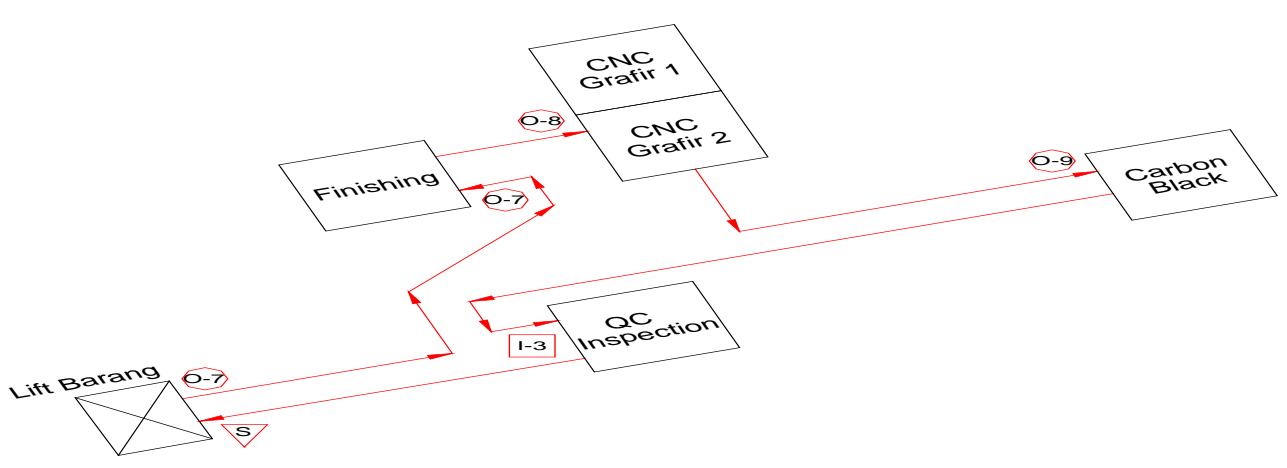

LAYOUT MESIN LANTAI 1

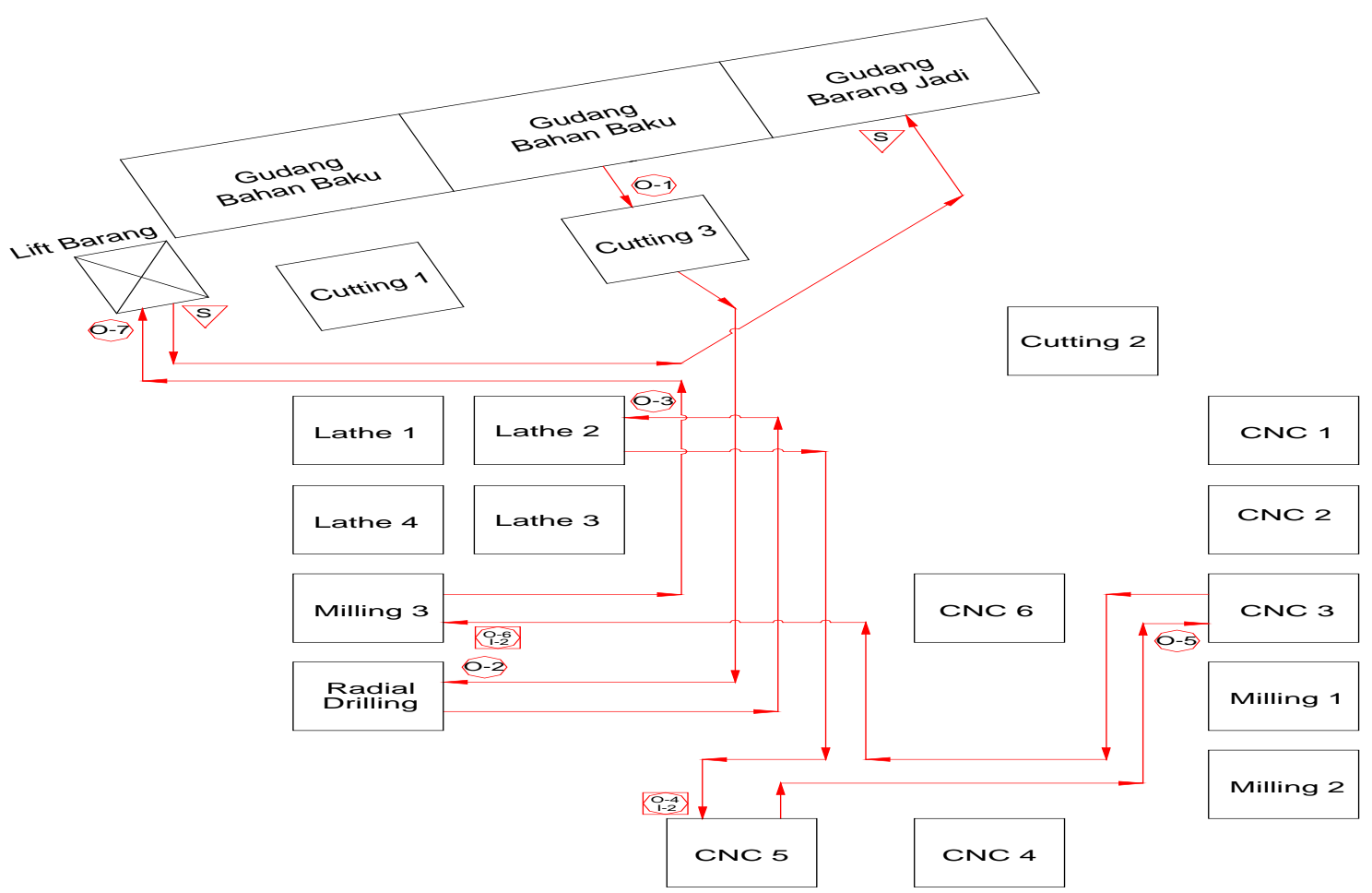

Gambar 1. Aliran Proses Produksi Access Fitting 


\section{TINJAUAN PUSTAKA}

\section{Perancangan Fasilitas}

Pengertian dasar mengenai perancangan fasilitas adalah perencanaan dan pengintegrasian suatu lintasan dari komponenkomponen produk untuk memperoleh keterkaitan paling efektif dan ekonomis antar manusia, peralatan dan pergerakan material. Rancangan digambarkan sebagai penataan fasilitas seperti peralatan, area tanah, bangunan, perlengkapan untuk mengoptimalkan hubungan antara operasi, aliran material dan informasi. Perancangan fasilitas juga merupakan metode yang diperlukan untuk mencapai efisiensi, tingkat ekonomis dan keamanan kerja [1]. Perancangan fasilitas sangat penting dan harus diperhatikan lebih mendalam karena mempengaruhi efisiensi operasional dalam perusahaan. Dalam proses perancangan fasilitas, aliran material dapat menggambarkan produktivitas dari fasilitas yang ada dan direncanakan dengan lebih teratur [1]. Konsep dasar perancangan fasilitas adalah sebagai berikut:

a. Perencanaan aliran material yang efisien merupakan syarat utama dalam produksi karena rancangan fasilitas berkenaan langsung dengan efisiensi kerja dan biaya perpindahan material.

b. Pola aliran material menjadi basis dari penataan fasilitas yang efektif.

c. Material handling mengubah pola aliran statis menjadi dinamis, sehingga dapat diketahui informasi pergerakan material yang dapat dirancang dengan lebih efisien sehingga dapat menekan biaya.

d. Penataan fasilitas yang efektif pada pola aliran material harus menghasilkan efisiensi langkah pada berbagai jenis proses.

e. Langkah proses yang efisien harus mampu menekan biaya produksi.

f. Biaya produksi yang dapat ditekan dapat meningkatkan keuntungan.

Analisis aliran bahan dapat dilakukan dengan menggunakan dua metode, yaitu analisis kuantitatif aliran bahan dan analisis kualitatif aliran bahan. Analisis kuantitatif aliran bahan mengukur berdasarkan kuantitas material yang dipindahkan seperti berat, volume, jumlah unit satuan kuantitatif lainnya.
Peta yang umum digunakan untuk melakukan analiss kuantitatif ini adalah peta dari-ke. Teknik ini sangat berguna untuk kondisikondisi dimana banyak item yang mengalir melalui suatu area seperti bengkel permesinan, kantor, dan lain-lain [2]. Aliran bahan bisa diukur secara kualitatif menggunakan tolak ukur derajat kedekatan hubungan antara satu fasilitas dengan lainnya. Peta hubungan aktivitas adalah suatu cara atau teknik yang sederhana di dalam merencanakan tata letak fasilitas atau departemen berdasarkan dengan hubungan aktivitas yang sering dinyatakan dalam penilaian kualitatif dan cenderung berdasarkan perimbangan-pertimbangan yang bersifat subyektif dari masing-masing fasilitas atau departemen [2].

Operation Process Chart (OPC) adalah suatu diagram yang berisi informasi urutan proses-proses suatu produksi dan menggambarkan keseluruhan proses produksi [1]. Keuntungan menggunakan OPC yaitu:

a. Menggabungkan informasi aliran produksi dan langkah perakitan ke dalam penggambaran yang lebih lengkap.

b. Menunjukkan langkah yang akan dilakukan pada setiap komponen

c. Menunjukkan urutan setiap part

d. Menunjukkan hubungan antar part

e. Menunjukkan tingkat kebutuhan mesin, tenaga kerja dan peralatan

Process Chart merupakan tabel yang berisi pencatatan langkah-langkah dalam proses produksi. Fungsi dari Process Chart yaitu [1]:

a. Memberikan metode pencatatan semua langkah dalam suatu proses produksi

b. Menjalankan pemeriksaan secara rinci pada proses

c. Menjadi basis analisis proses seperti identifikasi pergerakan, waktu tunggu, menunjukkan jarak peralatan

d. Membentuk dasar penentuan biaya

e. Membentuk dasar perbandingan alternatif metode

From to Chart (FTC) kadang-kadang disebut juga sebagai trip frequency chart atau travel chart yaitu suatu teknik konvensional yang umum digunakan untuk perencanaan tata letak pabrik dan pemindahan bahan dalam suatu proses produksi. Teknik ini sangat berguna 
untuk kondisi-kondisi dimana banyak item yang mengalir melalui suatu area seperti job shop, bengkel pemesinan, kantor dan lain-lain. FTC merupakan penggambaran tentang beberapa total $\mathrm{OMH}$ dari suatu bagian aktivitas dalam pabrik menuju pabrik lainnya. Sehingga dari peta ini dapat dilihat ongkos material handling dari dan ke masing-masing departemen secara keseluruhan, mulai dari gudang bahan baku (Receiving) menuju pabrikasi, Assembling dan terakhir gudang barang jadi (Shipping) [3].

Inflow digunakan untuk mencari koefisien ongkos yang masuk dari suatu departemen ke departemen lainnya. Outflow digunakan untuk mencari koefisien ongkos yang keluar dari suatu departemen ke departemen lainnya [3].

Input perhitungan inflow-outflow yaitu dari OMH dan FTC, yaitu ongkos yang dibutuhkan untuk material handling dari satu mesin ke mesin lainnya dan sebaliknya [3].

In Flow dari $\mathrm{A}$ ke $\mathrm{B}=$ Nilai ongkos dari A ke B

Total ongkos yang masuk ke departemen $\mathrm{B}$

Out Flow dari A ke B =

Nilai ongkos dari A ke B

Total ongkos yang keluar dari departemen $\mathrm{B}$

\section{Tabel Skala Prioritas (TSP)}

Tabel Skala Prioritas (TSP) adalah suatu tabel yang menggambarkan urutan prioritas antar departemen/mesin dalam suatu layout produksi dimana urutan prioritas antar departemen tersebut merupakan letak departemen optimal yang didapat dari hasil outflow dengan letak departemen sebelumnya. Input TPS didapat dari perhitungan outflow, dimana prioritas diurutkan berdasarkan harga koefisien ongkos outflow mulai dari nilai yang terbesar [4].

Tujuan pembuatan TSP adalah untuk meminimumkan ongkos, mengoptimalkan layout, memperkecil jarak handling.

\section{Activity Relationship Diagram (ARD)}

ARD adalah diagram hubungan antar aktivitas (departemen/mesin) berdasarkan tingkat prioritas kedekatan, sehingga diharapkan ongkos handling minimum. Dasar untuk ARD yaitu TSP. Jadi yang menempati prioritas pertama pada TSP harus didekatkan letaknya lalu diikuti prioritas berikutnya [5].

\section{Area Allocation Diagram (AAD)}

Area Allocation Diagram

(AAD)

merupakan gambaran layout secara global yang menggambarkan hubungan kedekatan antar departemen dengan skala ukuran luas lantai yang sebenarnya. Input dari pembuatan AAD ini adalah Area Relation Diagram dan data luas lantai setiap departemen. Ukuran setiap departemen pada AAD akan disesuaikan dengan luas lantai dan tata letak awal pada ARD yang telah terbentuk [6].

\section{Template}

Template merupakan suatu gambaran yang lebih jelas dari tata letak pabrik yang akan dibuat dan merupakan gambaran detail dari Area Allocation Diagram (AAD) yang telah dibuat. Apabila luas tanah yang ada terbatas maka sabagai pemecah masalah terebut adalah dengan mengefisiensikan luas tanah yang tersedia untuk pemanfaatan penempatan fasilitas, produksi, dan perkantoran.

Adanya pemisahan lantai antara bagian perkantoran dan produksi merupakan jalan keluar yang terbaik, yaitu dengan mengikuti syarat-syarat sebagai berikut [7]:

1. Untuk template dengan satu lantai (Single Floor)

Untuk penempatan tata letak antara bagian produksi, pelayanan (service), dan perkantoran ditempatkan dalam satu lantai jika luas lahan yang tersedia masih mencukupi dan memungkinkan.

2. Untuk template dengan dua lantai atau lebih (Multi Floor)

Penempatan tata letak fasilitas antar bagian produksi, pelayanan (service), dan perkantoran mengalami pemisahan tata letak. Biasanya untuk bagian produksi ditempatkan pada bagian pertama agar memudahkan handling dan material maupun loading dari container ke receiving dan shipping ke container. Template jenis ini adalah sebagai solusi jika luas tanah yang tersedia tidak mencukupi. 


\section{METODE PENELITIAN}

Penelitian dilakukan di PT. Korosi Specindo yang berlokasi di Jalan Pangeran Jayakarta No.76 Jakarta. Data yang diambil berupa data primer dan data sekunder. Data primer yang digunakan dalam penelitian dikumpulkan dengan cara mengukur, observasi, serta diskusi dengan pihak yang berkepentingan di perusahaan. Data sekunder didapat dengan cara mengumpulkan informasi yang dibutuhkan dalam penelitian ini dari dokumen-dokumen perusahaan yang terkait dengan permasalahan penelitian ini. Berikut ini merupakan tahapantahapan dalam proses penelitian.
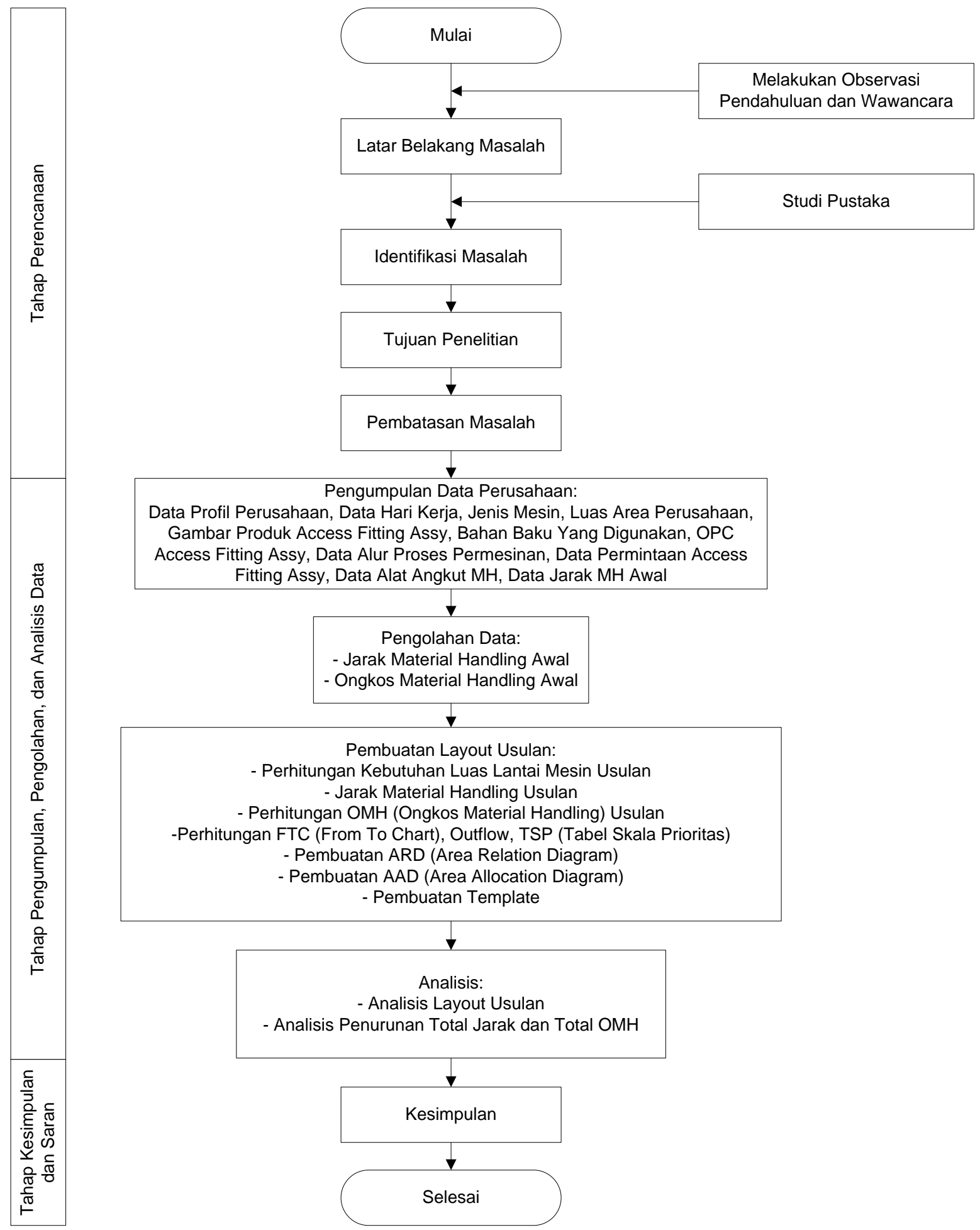

Gambar 2. Diagram Alir Metodologi Penelitian 


\section{HASIL DAN PEMBAHASAN}

PT. Korosi Specindo memiliki 2 lantai produksi. Lantai 1 digunakan untuk gudang bahan baku, mesin-mesin produksi, dan gudang barang jadi. Sedangkan lantai 2 digunakan untuk proses finishing, marking, dan assembly. Layout awal PT. Korosi specindo dapat dilihat pada Gambar 3.

Produk Access Fitting Assy terdiri beberapa komponen yaitu Access Fitting, Protective Cover, Solid Plug Coupon Holder, dan Strip Coupon. Proses poduksi Access Fitting Assy yang dilakukan di PT. Korosi Specindo menggunakan bahan baku material Carbon Steel dan Stainless Steel.

\section{Perhitungan Total Jarak Material Handling \\ Layout Awal}

Pada proses pembuatan Accesss Fitting Assy dilakukan pengukuran total jarak material handling yang dapat dilihat pada Tabel 1.

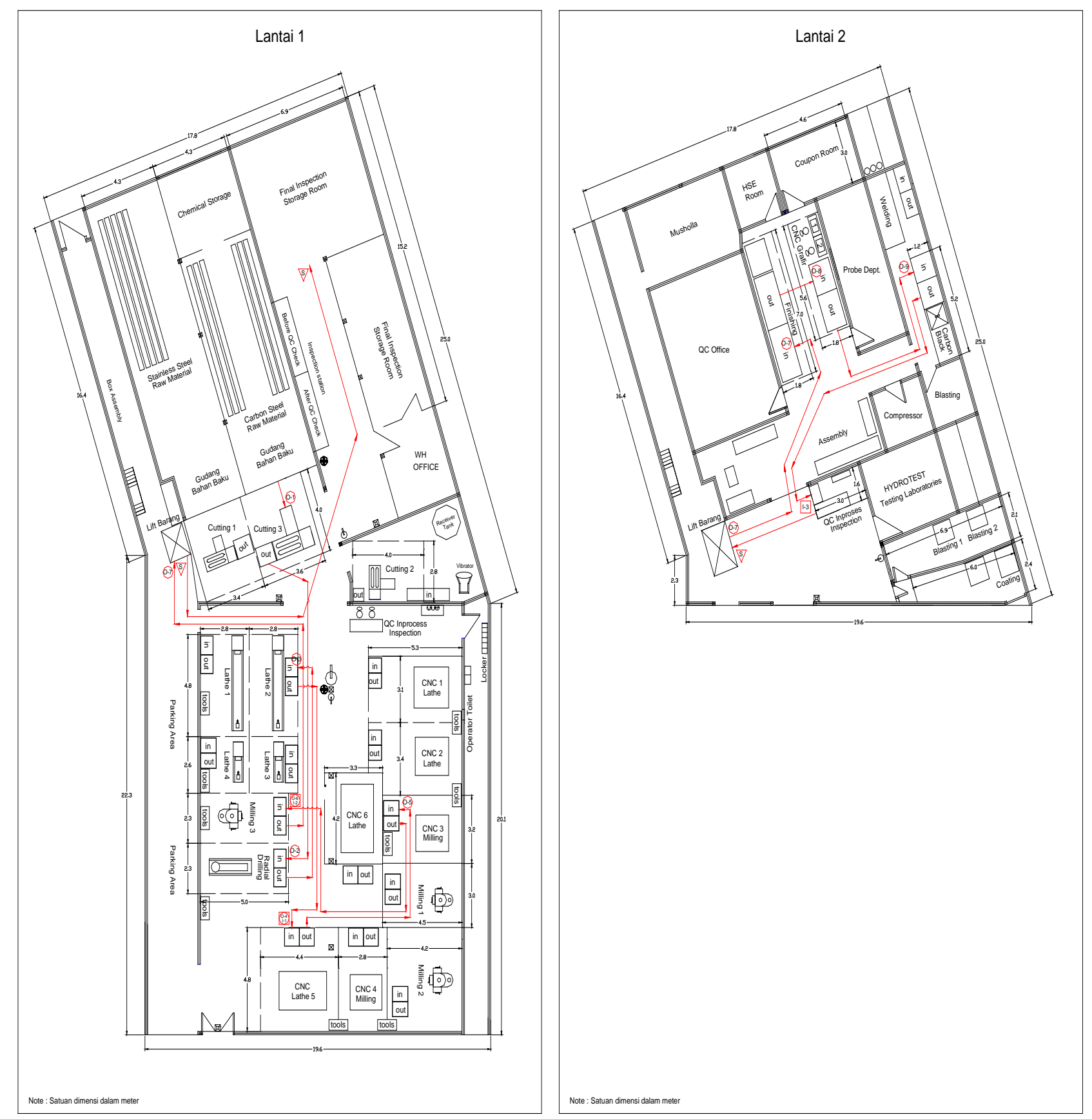

Gambar 3. Layout Awal PT. Korosi Specindo 
Tabel 1. Total jarak Material Handling Acces Fitting Assy Awal

\begin{tabular}{|c|c|c|c|c|c|}
\hline No & From & To & $\begin{array}{c}\text { Jarak } \\
\text { (m) }\end{array}$ & Frekuensi & $\begin{array}{c}\text { Total Jarak } \\
(\mathrm{m}) \\
\end{array}$ \\
\hline 1 & Gudang Bahan Baku & Cutting 1 & 10,1 & 1 & 10,1 \\
\hline 2 & Gudang Bahan Baku & Cutting 2 & 14,6 & 1 & 14,6 \\
\hline 3 & Gudang Bahan Baku & Cutting 3 & 9,6 & 1 & 9,6 \\
\hline 4 & Cutting 1 & Lathe 3 & 14,8 & 1 & 14,8 \\
\hline 5 & Cutting 1 & Lathe 4 & 14,4 & 1 & 14,4 \\
\hline 6 & Cutting 2 & Lathe 1 & 11,8 & 1 & 11,8 \\
\hline 7 & Cutting 2 & Milling 1 & 23,8 & 1 & 23,8 \\
\hline 8 & Cutting 3 & Radial Drilling & 16,3 & 2 & 32,6 \\
\hline 9 & Lathe 3 & CNC 1 & 6,8 & 1 & 6,8 \\
\hline 10 & Lathe 4 & CNC 1 & 10,8 & 1 & 10,8 \\
\hline 11 & Lathe 1 & CNC 2 & 15,3 & 1 & 15,3 \\
\hline 12 & Milling 1 & Finishing & 43,9 & 1 & 43,9 \\
\hline 13 & Radial Drilling & Lathe 2 & 8,6 & 2 & 17,2 \\
\hline 14 & CNC 1 & CNC 4 & 17,5 & 1 & 17,5 \\
\hline 15 & CNC 1 & Milling 1 & 19,7 & 1 & 19,7 \\
\hline 16 & CNC 2 & Milling 2 & 14,2 & 1 & 14,2 \\
\hline 17 & Finishing & CNC Grafir 2 & 3,2 & 1 & 3,2 \\
\hline 18 & Lathe 2 & CNC 5 & 11,8 & 2 & 23,6 \\
\hline 19 & CNC 4 & Milling 2 & 4,2 & 1 & 4,2 \\
\hline 20 & Milling 1 & Finishing & 43,9 & 1 & 43,9 \\
\hline 21 & Milling 2 & Finishing & 46,9 & 1 & 46,9 \\
\hline 22 & CNC Grafir 2 & Sand Blasting 1 & 17,6 & 1 & 17,6 \\
\hline 23 & CNC 5 & CNC 3 & 10,2 & 2 & 20,4 \\
\hline 24 & Milling 2 & Finishing & 46,9 & 1 & 46,9 \\
\hline 25 & Finishing & CNC Grafir 2 & 3,2 & 1 & 3,2 \\
\hline 26 & Finishing & CNC Grafir 1 & 3,2 & 1 & 3,2 \\
\hline 27 & Sand Blasting 1 & Timbangan & 23,3 & 1 & 23,3 \\
\hline 28 & CNC 3 & Milling 3 & 12,2 & 2 & 24,4 \\
\hline 29 & Finishing & CNC Grafir 1 & 3,2 & 1 & 3,2 \\
\hline 30 & CNC Grafir 2 & Inspeksi QC & 10,2 & 1 & 10,2 \\
\hline 31 & CNC Grafir 1 & Carbon Black & 11,6 & 1 & 11,6 \\
\hline 32 & Timbangan & Inspeksi QC & 16,6 & 1 & 16,6 \\
\hline 33 & Milling 3 & Finishing & 48,9 & 2 & 97,8 \\
\hline 34 & CNC Grafir 1 & Sand Blasting 2 & 17,6 & 1 & 17,6 \\
\hline 35 & Inspeksi QC & Gudang Barang Jadi & 32,3 & 1 & 32,3 \\
\hline 36 & Carbon Black & Inspeksi QC & 12,7 & 1 & 12,7 \\
\hline 37 & Inspeksi QC & Gudang Barang Jadi & 32,3 & 1 & 32,3 \\
\hline 38 & Finishing & Marking & 3,2 & 2 & 6,4 \\
\hline 39 & Sand Blasting 2 & Coating & 3,5 & 1 & 3,5 \\
\hline 40 & Inspeksi QC & Gudang Barang Jadi & 32,3 & 1 & 32,3 \\
\hline 41 & Marking & Carbon Black & 32,3 & 2 & 64,6 \\
\hline 42 & Coating & Inspeksi QC & 10,8 & 1 & 10,8 \\
\hline 43 & Carbon Black & Inspeksi QC & 12,7 & 2 & 25,4 \\
\hline 44 & Inspeksi QC & Gudang Barang Jadi & 32,3 & 1 & 32,3 \\
\hline 45 & Inspeksi QC & Gudang Barang Jadi & 32,3 & 2 & 64,6 \\
\hline \multicolumn{5}{|c|}{ Total } & 1036,8 \\
\hline
\end{tabular}

\section{Perhitungan Total Ongkos Material Perhitungan Total Jarak Material Handling Handling Layout Awal \\ Layout Usulan}

Dari OPC produk Access Fitting Assy yang telah diketahui, selanjutnya dilakukan pembuatan layout mesin usulan. Kemudian dilakukan pengukuran jarak menggunakan simulasi gambar dan disesuaikan dengan 
lintasan alat material handling. Hasil layout usulan dapat dilihat pada Tabel 3. Pengukuran total jarak material handling

Tabel 2. Total Ongkos Material Handling Layout Awal

\begin{tabular}{|c|c|c|c|c|c|c|}
\hline No & From & To & Alat Angkut & $\begin{array}{c}\text { OMH/m } \\
(\mathrm{Rp} / \mathrm{m})\end{array}$ & $\begin{array}{c}\text { Total Jarak } \\
\text { (m) }\end{array}$ & $\begin{array}{c}\text { OMH } \\
\text { (Rp) }\end{array}$ \\
\hline 1 & Gudang Bahan Baku & Cutting 1 & & 10,5 & 10,1 & 106,05 \\
\hline 2 & Gudang Bahan Baku & Cutting 2 & Manual Forklift & 10,5 & 14,6 & 153,3 \\
\hline 3 & Gudang Bahan Baku & Cutting 3 & Manual Forklift & 10,5 & 9,6 & 100,8 \\
\hline 4 & Cutting 1 & Lathe 3 & Manual Forklift & 10,5 & 14,8 & 155,4 \\
\hline 5 & Cutting 1 & Lathe 4 & Manual Forklift & 10,5 & 14,4 & 151,2 \\
\hline 6 & Cutting 2 & Lathe 1 & Manual Forklift & 10,5 & 11,8 & 123,9 \\
\hline 7 & Cutting 2 & Milling 1 & Manual Forklift & 10,5 & 23,8 & 249,9 \\
\hline 8 & Cutting 3 & Radial Drilling & Manual Forklift & 10,5 & 32,6 & 342,3 \\
\hline 9 & Lathe 3 & CNC 1 & Hand Pallet & 9,5 & 6,8 & 64,6 \\
\hline 10 & Lathe 4 & CNC 1 & Hand Pallet & 9,5 & 10,8 & 102,6 \\
\hline 11 & Lathe 1 & CNC 2 & Manual Forklift & 10,5 & 15,3 & 160,65 \\
\hline 12 & Milling 1 & Finishing & Trolley & 7,44 & 43,9 & 326,616 \\
\hline 13 & Radial Drilling & Lathe 2 & Manual Forklift & 10,5 & 17,2 & 180,6 \\
\hline 14 & CNC 1 & CNC 4 & Hand Pallet & 9,5 & 17,5 & 166,25 \\
\hline 15 & CNC 1 & Milling 1 & Hand Pallet & 9,5 & 19,7 & 187,15 \\
\hline 16 & CNC 2 & Milling 2 & Manual Forklift & 10,5 & 14,2 & 149,1 \\
\hline 17 & Finishing & CNC Grafir 2 & Trolley & 7,44 & 3,2 & 23,808 \\
\hline 18 & Lathe 2 & CNC 5 & Manual Forklift & 10,5 & 23,6 & 247,8 \\
\hline 19 & CNC 4 & Milling 2 & Hand Pallet & 9,5 & 4,2 & 39,9 \\
\hline 20 & Milling 1 & Finishing & Trolley & 7,44 & 43,9 & 326,616 \\
\hline 21 & Milling 2 & Finishing & Trolley & 7,44 & 46,9 & 348,936 \\
\hline 22 & CNC Grafir 2 & Sand Blasting 1 & Trolley & 7,44 & 17,6 & 130,944 \\
\hline 23 & CNC 5 & CNC 3 & Manual Forklift & 10,5 & 20,4 & 214,2 \\
\hline 24 & Milling 2 & Finishing & Trolley & 7,44 & 46,9 & 348,936 \\
\hline 25 & Finishing & CNC Grafir 2 & Trolley & 7,44 & 3,2 & 23,808 \\
\hline 26 & Finishing & CNC Grafir 1 & Trolley & 7,44 & 3,2 & 23,808 \\
\hline 27 & Sand Blasting 1 & Timbangan & Trolley & 7,44 & 23,3 & 173,352 \\
\hline 28 & CNC 3 & Milling 3 & Manual Forklift & 10,5 & 24,4 & 256,2 \\
\hline 29 & Finishing & CNC Grafir 1 & Trolley & 7,44 & 3,2 & 23,808 \\
\hline 30 & CNC Grafir 2 & Inspeksi QC & Trolley & 7,44 & 10,2 & 75,888 \\
\hline 31 & CNC Grafir 1 & Carbon Black & Trolley & 7,44 & 11,6 & 86,304 \\
\hline 32 & Timbangan & Inspeksi QC & Trolley & 7,44 & 16,6 & 123,504 \\
\hline 33 & Milling 3 & Finishing & Trolley & 7,44 & 97,8 & 727,632 \\
\hline 34 & CNC Grafir 1 & Sand Blasting 2 & Trolley & 7,44 & 17,6 & 130,944 \\
\hline 35 & Inspeksi QC & Gudang Barang Jadi & Trolley & 7,44 & 32,3 & 240,312 \\
\hline 36 & Carbon Black & Inspeksi QC & Trolley & 7,44 & 12,7 & 94,488 \\
\hline 37 & Inspeksi QC & Gudang Barang Jadi & Trolley & 7,44 & 32,3 & 240,312 \\
\hline 38 & Finishing & Marking & Trolley & 7,44 & 6,4 & 47,616 \\
\hline 39 & Sand Blasting 2 & Coating & Trolley & 7,44 & 3,5 & 26,04 \\
\hline 40 & Inspeksi QC & Gudang Barang Jadi & Trolley & 7,44 & 32,3 & 240,312 \\
\hline 41 & Marking & Carbon Black & Trolley & 7,44 & 64,6 & 480,624 \\
\hline 42 & Coating & Inspeksi QC & Trolley & 7,44 & 10,8 & 80,352 \\
\hline 43 & Carbon Black & Inspeksi QC & Trolley & 7,44 & 25,4 & 188,976 \\
\hline 44 & Inspeksi QC & Gudang Barang Jadi & Trolley & 7,44 & 32,3 & 240,312 \\
\hline 45 & Inspeksi QC & Gudang Barang Jadi & Trolley & 7,44 & 64,6 & 480,624 \\
\hline \multicolumn{6}{|c|}{ Total } & 8666,122 \\
\hline
\end{tabular}


Tabel 3. Total Jarak Material Handling Acces Fitting Assy Usulan

\begin{tabular}{|c|c|c|c|c|c|}
\hline No & From & To & $\begin{array}{c}\text { Jarak } \\
\text { (m) }\end{array}$ & Frekuensi & $\frac{\text { Total Jarak }}{\text { (m) }}$ \\
\hline \multirow{2}{*}{1} & \multirow{2}{*}{ Gudang Bahan Baku } & \multirow{2}{*}{ Cutting 1} & 10,1 & 1 & 10,1 \\
\hline & & & 10,1 & 1 & 10,1 \\
\hline \multirow{2}{*}{2} & \multirow{2}{*}{ Gudang Bahan Baku } & \multirow{2}{*}{ Cutting 2} & 14,6 & 1 & 14,6 \\
\hline & & & 14,6 & 1 & 14,6 \\
\hline 3 & Gudang Bahan Baku & Cutting 3 & 14,6 & 1 & 14,6 \\
\hline 4 & Cutting 1 & Lathe 3 & 15 & 1 & 15 \\
\hline 5 & Cutting 1 & Lathe 4 & 16,3 & 1 & 16,3 \\
\hline 6 & Cutting 2 & Lathe 1 & 12,6 & 1 & 12,6 \\
\hline 7 & Cutting 2 & Milling 1 & 7,1 & 1 & 7,1 \\
\hline 8 & Cutting 3 & Radial Drilling & 9,2 & 2 & 18,4 \\
\hline 9 & Lathe 3 & CNC 1 & 5,3 & 1 & 5,3 \\
\hline 10 & Lathe 4 & CNC 1 & 5,2 & 1 & 5,2 \\
\hline 11 & Lathe 1 & CNC 2 & 8,4 & 1 & 8,4 \\
\hline 12 & Milling 1 & Finishing & 17,9 & 1 & 17,9 \\
\hline 13 & Radial Drilling & Lathe 2 & 3,9 & 2 & 7,8 \\
\hline 14 & CNC 1 & CNC 4 & 9,7 & 1 & 9,7 \\
\hline 15 & CNC 1 & Milling 1 & 15,8 & 1 & 15,8 \\
\hline 16 & CNC 2 & Milling 2 & 10,2 & 1 & 10,2 \\
\hline 17 & Finishing & CNC Grafir 2 & 5,4 & 1 & 5,4 \\
\hline 18 & Lathe 2 & CNC 5 & 13,1 & 2 & 26,2 \\
\hline 19 & CNC 4 & Milling 2 & 4,8 & 1 & 4,8 \\
\hline 20 & Milling 1 & Finishing & 17,9 & 1 & 17,9 \\
\hline 21 & Milling 2 & Finishing & 20,1 & 1 & 20,1 \\
\hline 22 & CNC Grafir 2 & Sand Blasting 1 & 11,5 & 1 & 11,5 \\
\hline 23 & CNC 5 & CNC 3 & 6,7 & 2 & 13,4 \\
\hline 24 & Milling 2 & Finishing & 20,1 & 1 & 20,1 \\
\hline 25 & Finishing & CNC Grafir 2 & 5,4 & 1 & 5,4 \\
\hline 26 & Finishing & CNC Grafir 1 & 5,4 & 1 & 5,4 \\
\hline 27 & Sand Blasting 1 & Timbangan & 16 & 1 & 16 \\
\hline 28 & CNC 3 & Milling 3 & 5,5 & 2 & 11 \\
\hline 29 & Finishing & CNC Grafir 1 & 5,4 & 1 & 5,4 \\
\hline 30 & CNC Grafir 2 & Inspeksi QC & 4,7 & 1 & 4,7 \\
\hline 31 & CNC Grafir 1 & Carbon Black & 9,6 & 1 & 9,6 \\
\hline 32 & Timbangan & Inspeksi QC & 9,2 & 1 & 9,2 \\
\hline 33 & Milling 3 & Finishing & 22,4 & 2 & 44,8 \\
\hline 34 & CNC Grafir 1 & Sand Blasting 2 & 11,5 & 1 & 11,5 \\
\hline 35 & Inspeksi QC & Gudang Barang Jadi & 32,3 & 1 & 32,3 \\
\hline 36 & Carbon Black & Inspeksi QC & 12,7 & 1 & 12,7 \\
\hline 37 & Inspeksi QC & Gudang Barang Jadi & 32,3 & 1 & 32,3 \\
\hline 38 & Finishing & Marking & 5,4 & 2 & 10,8 \\
\hline 39 & Sand Blasting 2 & Coating & 3,5 & 1 & 3,5 \\
\hline 40 & Inspeksi QC & Gudang Barang Jadi & 32,3 & 1 & 32,3 \\
\hline 41 & Marking & Carbon Black & 9,6 & 2 & 19,2 \\
\hline 42 & Coating & Inspeksi QC & 10,8 & 1 & 10,8 \\
\hline 43 & Carbon Black & Inspeksi QC & 12,7 & 2 & 25,4 \\
\hline 44 & Inspeksi QC & Gudang Barang Jadi & 32,3 & 1 & 32,3 \\
\hline 45 & Inspeksi QC & Gudang Barang Jadi & 32,3 & 2 & 64,6 \\
\hline & & Total & & & 732,3 \\
\hline
\end{tabular}

Perhitungan Total Ongkos Material material handling layout usulan. Total ongkos Handling Layout Usulan

Setelah total jarak layout usulandiketahui material handling layout usulan dapat dilihat pada Tabel 4. tahap selanjutnya dilakukan perhitungn ongkos 
Tabel 4. Total Ongkos Material Handling Layout Usulan

\begin{tabular}{|c|c|c|c|c|c|c|}
\hline \multirow[t]{2}{*}{ No } & \multirow[t]{2}{*}{ From } & \multirow[t]{2}{*}{ To } & \multirow[t]{2}{*}{ Alat Angkut } & \multirow{2}{*}{$\begin{array}{c}\mathrm{OMH} / \mathrm{m} \\
(\mathrm{Rp} / \mathrm{m}) \\
\end{array}$} & \multirow{2}{*}{$\begin{array}{c}\begin{array}{c}\text { Total } \\
\text { Jarak }\end{array} \\
(\mathbf{m}) \\
\end{array}$} & \multirow{2}{*}{$\begin{array}{c}\text { OMH } \\
\text { (Rp) } \\
\end{array}$} \\
\hline & & & & & & \\
\hline \multirow{2}{*}{1} & Gudang Bahan & \multirow{2}{*}{ Cutting 1} & Manual Forklift & 10,5 & 10,1 & 106,05 \\
\hline & Baku & & Manual Forklift & 10,5 & 10,1 & 106,05 \\
\hline \multirow{2}{*}{2} & Gudang Bahan & \multirow{2}{*}{ Cutting 2} & Manual Forklift & 10,5 & 14,6 & 153,3 \\
\hline & Baku & & Manual Forklift & 10,5 & 14,6 & 153,3 \\
\hline 3 & $\begin{array}{c}\text { Gudang Bahan } \\
\text { Baku }\end{array}$ & Cutting 3 & Manual Forklift & & 14,6 & 153,3 \\
\hline 4 & Cutting 1 & Lathe 3 & Manual Forklift & 10,5 & 15 & 157,5 \\
\hline 5 & Cutting 1 & Lathe 4 & Manual Forklift & 10,5 & 16,3 & 171,15 \\
\hline 6 & Cutting 2 & Lathe 1 & Manual Forklift & 10,5 & 12,6 & 132,3 \\
\hline 7 & Cutting 2 & Milling 1 & Manual Forklift & 10,5 & 7,1 & 74,55 \\
\hline 8 & Cutting 3 & Radial Drilling & Manual Forklift & 10,5 & 18,4 & 193,2 \\
\hline 9 & Lathe 3 & CNC 1 & Hand Pallet & 9,5 & 5,3 & 50,35 \\
\hline 10 & Lathe 4 & CNC 1 & Hand Pallet & 9,5 & 5,2 & 49,4 \\
\hline 11 & Lathe 1 & CNC 2 & Manual Forklift & 10,5 & 8,4 & 88,2 \\
\hline 12 & Milling 1 & Finishing & Trolley & 7,44 & 17,9 & 133,176 \\
\hline 13 & Radial Drilling & Lathe 2 & Manual Forklift & 10,5 & 7,8 & 81,9 \\
\hline 14 & CNC 1 & CNC 4 & Hand Pallet & 9,5 & 9,7 & 92,15 \\
\hline 15 & CNC 1 & Milling 1 & Hand Pallet & 9,5 & 15,8 & 150,1 \\
\hline 16 & CNC 2 & Milling 2 & Manual Forklift & 10,5 & 10,2 & 107,1 \\
\hline 17 & Finishing & CNC Grafir 2 & Trolley & 7,44 & 5,4 & 40,176 \\
\hline 18 & Lathe 2 & CNC 5 & Manual Forklift & 10,5 & 26,2 & 275,1 \\
\hline 19 & CNC 4 & Milling 2 & Hand Pallet & 9,5 & 4,8 & 45,6 \\
\hline 20 & Milling 1 & Finishing & Trolley & 7,44 & 17,9 & 133,176 \\
\hline 21 & Milling 2 & Finishing & Trolley & 7,44 & 20,1 & 149,544 \\
\hline 22 & CNC Grafir 2 & Sand Blasting 1 & Trolley & 7,44 & 11,5 & 85,56 \\
\hline 23 & CNC 5 & CNC 3 & Manual Forklift & 10,5 & 13,4 & 140,7 \\
\hline 24 & Milling 2 & Finishing & Trolley & 7,44 & 20,1 & 149,544 \\
\hline 25 & Finishing & CNC Grafir 2 & Trolley & 7,44 & 5,4 & 40,176 \\
\hline 26 & Finishing & CNC Grafir 1 & Trolley & 7,44 & 5,4 & 40,176 \\
\hline 27 & Sand Blasting 1 & Timbangan & Trolley & 7,44 & 16 & 119,04 \\
\hline 28 & CNC 3 & Milling 3 & Manual Forklift & 10,5 & 11 & 115,5 \\
\hline 29 & Finishing & CNC Grafir 1 & Trolley & 7,44 & 5,4 & 40,176 \\
\hline 30 & CNC Grafir 2 & Inspeksi QC & Trolley & 7,44 & 4,7 & 34,968 \\
\hline 31 & CNC Grafir 1 & Carbon Black & Trolley & 7,44 & 9,6 & 71,424 \\
\hline 32 & Timbangan & Inspeksi QC & Trolley & 7,44 & 9,2 & 68,448 \\
\hline 33 & Milling 3 & Finishing & Trolley & 7,44 & 44,8 & 333,312 \\
\hline 34 & CNC Grafir 1 & Sand Blasting 2 & Trolley & 7,44 & 11,5 & 85,56 \\
\hline 35 & Inspeksi QC & Gudang Barang Jadi & Trolley & 7,44 & 32,3 & 240,312 \\
\hline 36 & Carbon Black & Inspeksi QC & Trolley & 7,44 & 12,7 & 94,488 \\
\hline 37 & Inspeksi QC & Gudang Barang Jadi & Trolley & 7,44 & 32,3 & 240,312 \\
\hline 38 & Finishing & Marking & Trolley & 7,44 & 10,8 & 80,352 \\
\hline 39 & Sand Blasting 2 & Coating & Trolley & 7,44 & 3,5 & 26,04 \\
\hline 40 & Inspeksi QC & Gudang Barang Jadi & Trolley & 7,44 & 32,3 & 240,312 \\
\hline 41 & Marking & Carbon Black & Trolley & 7,44 & 19,2 & 142,848 \\
\hline 42 & Coating & Inspeksi QC & Trolley & 7,44 & 10,8 & 80,352 \\
\hline 43 & Carbon Black & Inspeksi QC & Trolley & 7,44 & 25,4 & 188,976 \\
\hline 44 & Inspeksi QC & Gudang Barang Jadi & Trolley & 7,44 & 32,3 & 240,312 \\
\hline 45 & Inspeksi QC & Gudang Barang Jadi & Trolley & 7,44 & 64,6 & 480,624 \\
\hline & & Tot & & & & 6176,184 \\
\hline
\end{tabular}


Template layout usulan dapat dilihat pada Gambar 5.
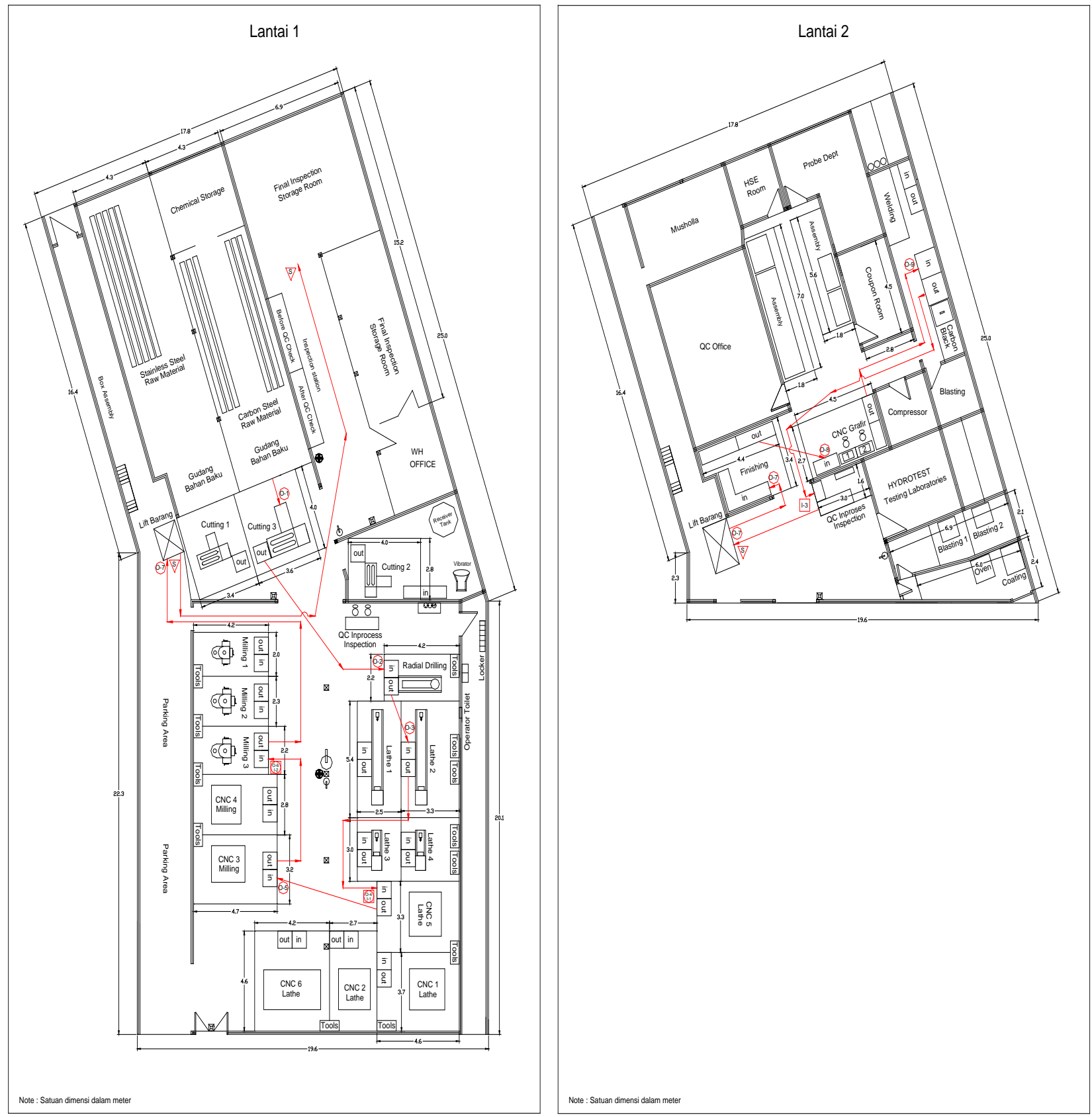

Gambar 5. Layout Usulan PT. Korosi Specindo

\section{Analisis Layout Usulan}

Dari Template layout usulan yang telah dibuat terlihat perbedaan dengan layout awal. Pada layout awal penempatan posisi mesinnya kurang tepat dan tidak memperhatikan aliran proses produksi. Sedangkan pada layout usulan mesin-mesin disusun berdasarkan tipe tata letak proses (Process Layout), yaitu pengaturan penempatan mesin dikelompokkan berdasarkan fungsi kerja pada sistem operasi yang sejenis ke dalam satu departemen. Aliran perpindahan material menjadi lebih teratur dan tidak terjadi aliran bolak-balik, sehingga jarak lintasan material handling menjadi lebih pendek dibandingkan layout awal.

\section{Analisis Penurunan Total Jarak dan Total OMH}

Analisis ini digunakan untuk mengetahui besarnya penurunan total jarak dan total ongkos 
material handling pada tata letak usulan. Untuk mengetahui penurunan total jarak maka total jarak awal dikurangi total jarak usulan, dan hasilnya sebagai berikut:

Penurunan Total Jarak

$$
\begin{aligned}
& =\text { Total Jarak Awal }- \text { Total Jarak Usualan } \\
& =1036,8-732,3 \\
& =304,5 \text { meter }
\end{aligned}
$$

Dihitung dalam persentase menjadi:

Penurunan Total Jarak

$$
\begin{aligned}
& =\frac{\text { Total Jarak Usulan }- \text { Total Jarak Awal }}{\text { Total Jarak Awal }} \times 100 \% \\
& =\frac{732,3-1036,8}{1036,8} \times 100 \% \\
& =29,36 \%
\end{aligned}
$$

Penurunan Total Ongkos Material Handling

Untuk mengetahui penurunan total $\mathrm{OMH}$ maka total $\mathrm{OMH}$ awal dikurangi total $\mathrm{OMH}$ usulan, dan hasilnya sebagai berikut:

Penurunan Total OMH

$$
=\text { Total OMH Awal }- \text { Total OMH Usulan }
$$$$
=\text { Rp. 8.666,122 }- \text { Rp. 6.176,184 }
$$$$
=\text { Rp. } 2 \cdot 489,938
$$

Dihitung dalam persentase menjadi:

Penurunan Total OMH

$$
\begin{aligned}
& =\frac{\text { Total OMH Usulan }- \text { Total OMH Awal }}{\text { Total OMH Awal }} \times 100 \% \\
& =\frac{\text { Rp. 6.176,184 }- \text { Rp. } 8.666,122}{\text { Rp. 8.666,122 }} \times 100 \% \\
& =28,73 \%
\end{aligned}
$$

\section{KESIMPULAN}

Berdasarkan hasil dari pengolahan data dan analisis rancangan tata letak yang sudah dilakukan dapat ditarik kesimpulan yaitu: layout usulan memperbaiki aliran perpindahan material dan proses produksi Access Fitting Assy menjadi lebih teratur. Terjadi penurunan jarak material handling dari total jarak awal sebesar 1036,8 meter dengan layout usulan menjadi 732,3 meter. Persentase penurunan total jarak sebesar 29,36\%. Terjadi penurunan ongkos material handling dari total ongkos material handling awal sebesar Rp. 8.666,122 dengan layout usulan menjadi Rp. 6.176,184. Persentase penurunan ongkos material handling sebesar $28,73 \%$.

\section{DAFTAR PUSTAKA}

[1]. Apple, James M., 1990, Tata Letak Pabrik dan Pemindahan Bahan, Edisi Ketiga, ITB, Bandung.

[2]. Wignjosoebroto, 2003, Sritomo, Tata Letak Pabrik dan Pemindahan Bahan, Edisi Ketiga, Surabaya: Penerbit Guna Widya.

[3]. Hadiguna, R. A. Dan Setiawan, H., 2010, Tata Letak Pabrik. Edisi Pertama, Yogyakarta: Andi.

[4]. Purnomo, Hari, 2004, Perencanaan dan Perancangan Fasilitas, Yogyakarta: Penerbit CV.Andi Offset.

[5]. Tomkins James A. and White John A., 1984, Facilities Planning. John Wiley \& Sons Inc., Canada.

[6]. Heragu, Sunderesh S., 2008, Facilities Design (3rd ed), Clermont, FL: CRC Press.

[7]. Styoko, 2012, Suatu Tinjauan Terhadap Tata Letak Pabrik untuk Meningkatkan Produktivitas, Orbith Vol.8 No.2, Semarang. 